\title{
Non-Invasive Assessment of Esophageal Varices in Patients with Liver Cirrhosis
}

\author{
Kiran Namoos ${ }^{1}$, Waqas Shabbir ${ }^{2}$, Imran Ali Zaidi ${ }^{3}$
}

Assistant Professor of Biochemistry, Shalamar Medical \& Dental College, Lahore Pakistan

1 Conception $\mathcal{E}$ design, Manuscript writing, Interpretation of data $\mathcal{E}$ analysis

2 Assistant Professor of Gastroenterology, Lahore General Hospital, Lahore Pakistan

2 Collection and assembly of data $\mathcal{E}$ statistical expertise

3 Assistant Professor of Biochemistry, Fatima Memorial Hospital College of Medicine E Dentistry Lahore Pakistan

3 Results Compiling, Interpretation of data $\mathcal{E}$ Analysis

\author{
Submitted for Publication: 23-07-202 \\ Accepted for Publication 12-11-2020 \\ CORRESPONDING AUTHOR \\ Dr. Kiran Namoos, \\ Assistant Professor, Department of Biochemistry \\ Shalamar Medical \& Dental College, Lahore Pakistan \\ Email:knamoos@hotmail.com
}

\section{ABSTRACT}

Background: Esophageal variceal related bleeding is a lethal outcome of portal hypertension in patients with cirrhosis with mortality. Objective: To assess esophageal varices in patients with liver cirrhosis using non-invasive parameters. Study Design: Cross sectional study. Settings: Gastroenterology Department, Lahore General Hospital, Lahore Pakistan. Duration: 6 months from September 2016 to February 2017. Methodology: Data of all cirrhotic patients admitted in medical ward was collected. Liver cirrhosis was confirmed by abdominal ultrasound. Values of platelet count, serum albumin and serum ALT estimated by automated biochemistry analyzer. Serum ALT / platelet ratio index was measured by formula. Results: It is observed that esophageal varices are most common in middle to old age. $53.9 \%$ of the cirrhosis patients of the age greater than 40 years have esophageal varices. Mean age of patients with esophageal varices (EV) was 40.94 year. Average duration of cirrhosis was 3.09 years and level of serum alanine aminotransferase (ALT) was raised with thrombocytopenia and low serum albumin. Aspartate aminotransferase / platelet ratio (APRI) index was raised as compared to patients without esophageal varices. Conclusion: Esophageal varices are most common in middle to old age and non-invasive assessment including level of serum alanine aminotransferase, aspartate aminotransferase, serum albumin, platelet count and APRI ratio may help to assess esophageal varices in patients with liver cirrhosis.

Keywords: Esophageal varices, Non-invasive assessment, Liver cirrhosis.

How to Cite: Namoos K, Shabbir W, Zaidi IA. Non-Invasive Assessment of Esophageal Varices in Patients with Liver Cirrhosis. APMC 2020;14(4):328-30. DOI: $10.29054 /$ APMC/2020.973

\section{INTRODUCTION}

Liver diseases, particular liver cirrhosis, are typified by fibrosis with advance stage and formation of nodules which are regenerative results in developmental distortion. This may increase the risk of number of complications. The most common complication of cirrhosis is portal hypertension results in esophageal varices. ${ }^{1}$ In developing countries like Pakistan, liver cirrhosis is more prevalent as compared to developed countries. $^{2}$

Esophageal varices occur due to blockade of blood flow to the liver. This results the flow of blood into blood vessels of small size and causes a rupture of blood vessels causing severe bleeding. The incidence of $\mathrm{EV}$ is related with severity of liver cirrhosis, thrombosis and infection due to parasites. Additionally, factors related with EV are age, reduced count of platelets and values of serum albumin as well as ascites. ${ }^{3}$

Bleeding is the gravest complication of EV and may lead to shock and death, if not treated in time in all age group. 3,4 Untreated EV results in bleeding in 30-40\% cases and many patients die due to this complication. The bleeding results in blood vomiting, black color stool, anemia, reduced urination and shock. ${ }^{5}$
Cirrhosis and esophageal varices can be developed with any age but most common is in middle age or age $>40$ years. Disparity in the mean age is related with etiology and incidence of viral hepatitis in different inhabitants and also the extent of viral infection. ${ }^{3}$

Ascites has many causes such as liver diseases, cancers, congestive heart failure, or kidney failure. The most common cause of ascites is advanced liver disease or cirrhosis. The first abnormality that develops appears to be portal hypertension. ${ }^{6}$

The most reliable method for assessing $\mathrm{EV}$ is the estimation of the hepatic venous pressure gradient. However, it is costly, invasive and not offered by all labs. Detection of markers of esophageal varices will permit upper gastrointestinal tract endoscopy in selected patients only. Hence needle interference and incidence of bleeding can be avoided.

Cross-sectional study was conducted to assess esophageal varices in patients with liver cirrhosis using non-invasive parameters.

METHODOLOGY

Study Design: Cross sectional study. 
Settings: Gastroenterology Department, Lahore General Hospital, Lahore Pakistan.

Duration: 6 months from September 2016 to February 2017

Sample Technique: Non-probability Purposive Sampling Technique.

Sample Size: 150 cases

Inclusion Criteria: All patients with history of liver cirrhosis of any gender and age between 20 to 60 years admitted in the medical ward were included.

Exclusion Criteria: Patients who were previously taking medicines to reduce portal hypertension, who underwent sclerotherapy or band ligation, suffering from hepatocellular carcinoma, previous portosystemic anastomosis or portal vein thrombosis and ascites were excluded from the study.

Data Collection Procedure: 150 consented patients of 2060 years of age with cirrhosis. Questionnaire based on clinical data and demographics was filled by patients. Liver cirrhosis / esophageal varices was confirmed by abdominal ultrasound, upper GI endoscopy. Study was approved by Institutional Review Board (IRB) of Lahore General Hospital, Lahore. Values of platelet count, serum albumin and serum ALT estimated by HITACHI automated biochemistry analyzer. Serum ALT / platelet ratio index was measured by formula.

Sample size of 150 cases is calculated with $95 \%$ confidence level, $6 \%$ margin of errors and taking expected percentage of esophageal varices i.e. $85 \%$ in patients of cirrhosis with ascites. $^{7}$

Data Analysis: Data was entered and analyzed into SPSS version 20. The quantitative data like age and duration of chronic liver disease was calculated as mean and standard deviation. The qualitative data like gender, esophageal varices was calculated as frequency and percentage.

\section{RESULTS}

Association of esophageal varices with age and gender is tabulated as Table I. It is observed that EV is most common in age greater than 40 years $(53.9 \%)$.

Table 1: Distribution of cases according to age groups and gender

\begin{tabular}{|c|c|c|c|}
\hline \multirow{2}{*}{ Variables } & \multirow{2}{*}{ Total } & \multicolumn{2}{|c|}{ Presence of esophageal varices } \\
\cline { 3 - 4 } & & $\begin{array}{c}\text { Positive for EV n } \\
(\mathbf{\%})\end{array}$ & $\begin{array}{c}\text { Negative for EV n } \\
\text { (\%) }\end{array}$ \\
\hline Male & 77 & $42(54.5 \%)$ & $35(45.4 \%)$ \\
\hline Female & 73 & $43(58.9 \%)$ & $30(41.1 \%)$ \\
\hline $\begin{array}{c}\text { Age (21-30) } \\
\text { yrs }\end{array}$ & 34 & $21(61.7 \%)$ & $13(38.2 \%)$ \\
\hline (31- 40) yrs & 40 & $23(57.5 \%)$ & $17(42.5 \%)$ \\
\hline (>40) yrs & 76 & $41(53.9 \%)$ & $35(46.1 \%)$ \\
\hline
\end{tabular}

Demographic and biochemical parameters showed that mean age of patients with varices was 40.94 year. More females $(58.9 \%)$ have esophageal varices as compared to males $(54.5 \%)$. Average duration of cirrhosis was 3.09 years in patients with varices. Level of serum ALT \& serum AST was raised with thrombocytopenia and low serum albumin was found. Mean AST/platelet ratio index or APRI was 2.46 in patients with varices. (Table II).

Table 2: Comparison of demographic and biochemical markers in relation with esophageal varices

\begin{tabular}{|c|c|c|c|}
\hline \multirow{2}{*}{ Variables } & \multicolumn{3}{|c|}{ Presence of esophageal varices } \\
\cline { 2 - 4 } & $\begin{array}{c}\text { Positive for } \\
\text { EV n }=\mathbf{8 5}\end{array}$ & $\begin{array}{c}\text { Negative for } \\
\text { EV } \mathbf{n}=\mathbf{6 5}\end{array}$ & $\mathbf{p}$ value \\
\hline Age (yrs) & $40.94 \pm 10.96$ & $40.28 \pm 10.87$ & 0.80 \\
\hline $\begin{array}{c}\text { Duration of } \\
\text { cirrhosis (yrs) }\end{array}$ & $3.09 \pm 1.35$ & $2.79 \pm 1.45$ & 0.51 \\
\hline $\begin{array}{c}\text { Platelet count } \\
\text { (ul) }\end{array}$ & $134.80 \pm 44.85$ & $174.82 \pm 55.80$ & 0.00 \\
\hline ALT (IU) & $70.35 \pm 49.43$ & $33.37 \pm 10.32$ & 0.00 \\
\hline AST (IU) & $50.57 \pm 32.00$ & $31.86 \pm 11.37$ & 0.02 \\
\hline $\begin{array}{c}\text { Serum Albumin } \\
\text { (g/dl) }\end{array}$ & $3.13 \pm 0.86$ & $3.55 \pm 0.9$ & 0.53 \\
\hline *APRI & $2.46 \pm 0.69$ & $1.9 \pm 0.8$ & 0.05 \\
\hline
\end{tabular}

* Aspartate amino transferase to platelet ratio index. Independent $t$ test is used to compare means. $p$ value significant if less than 0.05

\section{DISCUSSION}

Esophageal variceal bleeding is the most common complication of liver cirrhosis and the main reason of mortality in patients with cirrhosis. Clinical complication of portal hypertension is thrombocytopenia, ascites etc. ${ }^{8}$ $\mathrm{EV}$ is most common in middle to old age i.e. $>40$ years with $53.9 \%$. Male / female ratio is 1: 0.24 . We agreed with a study who observed that EV is observed in age range 18-26 year and 50 to 59 years with male female ratio 1:0.6. ${ }^{9}$ However, a study found no gender difference in patients with or without esophageal varices. ${ }^{8}$

According to our study the mean age of the patients was 40.94 years in patients with varices. Many studies observed that most of the individuals suffer with cirrhosis in the age of 40-60 years. It is demonstrated that age from 40 to onward cover the age at which most of the people are working and liver cirrhosis effects on the efficiency of patients and trouble in society. Study also stated that in this age group the complications of known afflictions of the liver are started. ${ }^{3}$ However, the mean age in studies carried out in developed countries were higher in comparison to studies carried out in developing world. ${ }^{10}$ According to present study duration of cirrhosis was 3.09 years in patients with varices. Level of ALT and AST was raised with thrombocytopenia. Decreased values of serum albumin were also observed. A study reported that 
pathogenesis of thrombocytopenia in cirrhotic patients is multi-factorial and comprises of reduced synthesis of thrombopoietin, sequestration of platelets via spleen, and suppression of platelet synthesis.11 We agreed with studies who found thrombocytopenia in EV. A group of workers stated that presence of EV in cirrhotic patients was confirmed by low platelet count. ${ }^{12,13}$ The present study shows significant association of APRI with varices. The study by De Mattos et al. has showed similar results and found significant association of APRI with varices. ${ }^{14}$ A study demonstrated that liver functions tests include the biochemical parameters associated with lysis of cell / inflammation (ALT / AST), and parameters that indicate the synthetic function of liver like albumin. These biochemical parameters are good indicators of steatosis and inflammation and may be a prediction of development of fibrosis. ${ }^{15}$ It is observed that low values of albumin in esophageal varices forecast portal hypertension with $97 \%$ accuracy and 100\% sensitivity. ${ }^{16}$

\section{CONCLUSION}

Esophageal varices are most common in middle to old age and non-invasive assessment including level of serum ALT and AST, serum albumin, platelet count and APRI ratio may help to assess Esophageal varices in patients with liver cirrhosis. It is suggested that screening of cirrhotic patients at the interval of 1-2 year without varices should be carried out with non-invasive parameter to evaluate the development of varices.

\section{LIMITATIONS}

Sample size is small. A single center study with a cross sectional design.

\section{SUGGESTIONS / RECOMMENDATIONS}

Further studies of APRI index with a definite cut-off value in a large population may be more informative.

\section{CONFLICT OF INTEREST / DISCLOSURE}

There was no conflict of interest and nothing to disclosed in this research.

\section{ACKNOWLEDGEMENTS}

We acknowledge the services of our hospital administration who helped in collection of data.

\section{REFERENCES}

1. Al-Busafi SA, McNabb-Baltar J, Farag A, Hilzenrat N. Clinical manifestations of portal hypertension. Int $\mathrm{J}$ Hepatol. 2012;2012:203794.

2. Ullah F, Khan S, Afridi AK, Rahman SU. Frequency of different causes of cirrhosis liver in local population. Gomal J Med Sci. 2012;10(2):178-81.

3. Ahmad I, Niaz Z, Mumtaz SU, Komal T, Waheed I, Abaidullah S. Comparison of Carvedilol and Propranolol in the Treatment of Portal Hypertension in Cirrhosis. Annals KEMU. 2019;24(4):92831.

4. Duah A, Nkrumah KN, Tachi K. Oesophageal varices in patients with liver cirrhosis attending a major tertiary hospital in Ghana. Pan Afr Med J. 2018;31:230.

5. Nicholls L, Montez J, Pelayo-Katsanis L, Katsanis E. Esophageal Varices in Adolescent and Young Adult Males with Acute Lymphocytic Leukemia. J of Adolesc Young Adult Oncol. 2019;8(2):217-20.

6. Biecker E. Gastrointestinal Bleeding in Cirrhotic Patients with Portal Hypertension. ISRN Hepatology. 2013;2013:541836.

7. Adebayo D, Neong SF, Wong F. Refractory Ascites in Liver Cirrhosis. Am J Gastroenterol. 2019;114(1):40-7.

8. Schechter RB, Lemme EM, Coelho HS. Gastroesophageal reflux in cirrhotic patients with esophageal varices without endoscopic treatment. Arq Gastroenterol. 2007;44(2):145-50.

9. Kraja B, Mone I, Akshija I, Koçollari A, Prifti S, Burazeri G. Predictors of esophageal varices and first variceal bleeding in liver cirrhosis patients. World J Gastroenterol. 2017;23(26):4806-14.

10. Romcea A, Tanțău M, Seicean A, Pascu O. Variceal bleeding in cirrhotic patients: risk factors, evolution, treatment. Clujul Med. 2013;86(2):107-10.

11. Mattos AZ, Mattos AA, Vianna FF, Musskopf MI, Pereira-Lima JC, Maciel AC. Platelet count/spleen diameter ratio: analysis of its capacity as a predictor of the existence of esophageal varices. Arq Gastroenterol. 2010;47(3):275-8.

12. Adami MR, Kieling CO, Schwengber FP, Hirakata VN, Vieira SMG. Noninvasive Methods of Predicting Large Esophageal Varices in Children with Intrahepatic Portal Hypertension. J Pediatr Gastroenterol Nutr. 2018;66(3):442-6.

13. Nada L, Samira el F, Bahija B, Adil I, Nourdine A. Noninvasive predictors of presence and grade of esophageal varices in viral cirrhotic patients. Pan Afr Med J. 2015;20:145.

14. Abd-Elsalam S, Habba E, Elkhalawany W, Tawfeek S, Elbatea H, El-Kalla F, et al. Correlation of platelets count with endoscopic findings in a cohort of Egyptian patients with liver cirrhosis. Medicine (Baltimore). 2016;95(23):e3853.

15. Wagh V, Mankoskar A. Platelet Count Spleen Diameter Ratio for non invasive Diagnosis of Esophageal Varices. J Adv Med Dent Scie Res. 2019;7(1):136-41.

16. Elias S, Masad B, Nimer A. Serum Biomarkers for Evaluating Portal Hypertension. Arch Med. 2016;8(4)153-66.

17. Karatzas A, Konstantakis C, Aggeletopoulou I, Kalogeropoulou C, Thomopoulos K, Triantos C. Non-invasive screening for esophageal varices in patients with liver cirrhosis. Ann Gastroenterol. 2018;31(3):305-14. 